\title{
The effects of brain stimulation of subthalamic nucleus surgery on gait and balance performance in Parkinson disease. A pilot study
}

Filiz Altuğ ${ }^{1}$, Feridun Acar², Göksemin Acar Uğur Cavlak $^{1}$

1School of Physical Therapy and Rehabilitation, Pamukkale University, Denizli, Turkey 2Department of Neurosurgery, Pamukkale University, Denizli, Turkey

${ }^{3}$ Department of Neurology, Pamukkale University, Denizli, Turkey

Submitted: 21 November 2011

Accepted: 11 May 2012

Arch Med Sci 2014; 10, 4: 733-738

DOI: 10.5114 /aoms.2012.31371

Copyright (C 2014 Termedia \& Banach

\section{Abstract}

Introduction: Parkinson's disease (PD) is a progressive neurodegenerative disorder characterized by tremor, rigidity and bradykinesia. Gait and postural difficulties supersede tremor, rigidity and bradykinesia as drivers of disease burden in patients with advanced PD. The aim of this study was to describe the effects of deep brain stimulation of the subthalamic nucleus on gait ability and balance performance in patients with PD.

Material and methods: We studied 19 consecutive patients who underwent bilateral stimulation of the subthalamic nucleus. Patients were evaluated preoperatively and at the $5^{\text {th }}$ day and $6^{\text {th }}$ month after surgery. Timed Up and Go Test, $12 \mathrm{~m}$ Walking Test, Chair Stand Test and Berg Balance Scale (BBS) were used to assess mobility and balance performance. Unified Parkinson's Disease Rating Scale (UPDRS III) and Hoehn and Yahr Scale were also used.

Results: All the patients' mobility ability and balance performance improved after surgery $(p<0.05)$. At the $6^{\text {th }}$ month after surgery, the Timed Up and Go Test scores were decreased from $56.05 \pm 42.52$ to $21.47 \pm 20.36$, the $12 \mathrm{~m}$ Walking Test scores were decreased from $100.44 \pm 66.44$ to $28.84 \pm 19.79$, the Chair Stand Test scores were increased from $4.00 \pm 4.66$ to $11.68 \pm 4.43$ and the BBS score was increased from $12.84 \pm 6.89$ to $38.89 \pm 8.79$. UPDRS total scores were significantly improved 6 months after surgery $(p<0.001)$. UPDRS total scores were decreased from $98.26 \pm 37.69$ to $39.36 \pm 18.85$. The Hoehn and Yahr Scale score was significantly decreased after surgery $(p<0.05)$.

Conclusions: Surgical therapy is an effective treatment to improve gait ability and balance performance in Parkinson's patients.

Key words: Parkinson's disease, balance performance, gait ability, subthalamic nucleus.

\section{Introduction}

Parkinson's disease (PD) is a progressive neurodegenerative disorder characterized by tremor, rigidity and bradykinesia [1]. The loss of dopamine producing neurons in the substantia nigra also affects gait, postural control and balance perform. Gait and postural difficulties supersede tremor, rigidity and bradykinesia as drivers of disease burden in patients with advanced PD [2]. Patients with PD suffer frequent falls, and the incidence of falls is closely related to the duration and severity of PD as well as

\author{
Corresponding author: \\ Assist. Prof. Filiz Altuğ \\ School of Physical Therapy \\ and Rehabilitation \\ Pamukkale University \\ Kınıklı Campus, 20070 \\ Denizli, Turkey \\ Phone/fax: +90258 2962299 \\ 2962322 \\ Mobile phone: \\ +905355625146 \\ E-mail: fkural@pau.edu.tr
}


the use of multiple medication [3]. Postural instability affects the ability to maintain balance during everyday tasks; it may severely incapacitate and restrict daily activities [4].

The management of PD is mainly pharmacological. Paradoxically, medication may even increase the risk of falling, for example due to drug-induced freezing episodes or violent dyskinesias [4, 5]. Alternative treatment strategies are therefore required. Exercise regimes for patients with PD improve physical functioning, strength, balance and gait speed. Moreover, there is a consensus in the literature that regular exercise practice improves physical and functional performance in different populations $[6,7]$. On the other hand, inactivity is considered an important factor in accelerating the degenerative process of PD [8]. Over the last decade high-frequency deep brain stimulation (DBS) of the subthalamic nucleus (STN) has emerged as an efficient therapy for patients with advanced PD [9]. A recent meta-analysis showed that bilateral STN stimulation appears to be somewhat more effective than bilateral pallidal stimulation in improving clinically rated balance and gait, particularly during the drug off state [5].

$A$ recent study reported that DBS in STN improved Berg Balance Scale (BBS) scores as well as postural stability and motor symptoms significantly. Seventy percent of their patients improved their total score of the BBS with DBS on compared with DBS off [10]. A study by Bakker et al. showed that DBS increased stride length and gait velocity comparably with an optimal dose of levodopa [11] and gait velocity and stride length improved on DBS [12]. Most studies showed that DBS results in an increased gait velocity, improved mobility and better postural control [1-5, 9-13]. The present work shows the pragmatic benefits of DBS of the STN in improving balance and mobility and decreasing motor symptoms of PD.

The aim of this study was to describe the effects of deep brain stimulation of the subthalamic nucleus

Table I. Demographic characteristics of patients included in study

\begin{tabular}{|lcc|}
\hline Variables & Min.-max. & $X \pm$ SD \\
\hline Age [years] & $37.00-72.00$ & $55.05 \pm 9.07$ \\
\hline Height [cm] & $150-180$ & $163 \pm 0.08$ \\
\hline Weight [kg] & $47.00-104.00$ & $68.57 \pm 15.30$ \\
\hline Body mass index [kg/m²] & $17.72-37.78$ & $25.65 \pm 6.09$ \\
\hline $\begin{array}{l}\text { Duration of disease } \\
\text { [years] }\end{array}$ & $3.00-25.00$ & $12.57 \pm 5.90$ \\
\hline $\begin{array}{l}\text { Duration of using } \\
\text { levodopa [years] }\end{array}$ & $3.00-25.00$ & $12.00 \pm 5.91$ \\
\hline $\begin{array}{l}\text { Equivalent daily dose } \\
\text { of LED [mg] }\end{array}$ & $0-1500$ & $648.68 \pm 446.93$ \\
\hline
\end{tabular}

on gait ability and balance performance in patients with PD. In this study, we expected to observe some improvements in terms of mobility including gait and balance improvements. The hypothesis was that STN DBS is an approach which improves the motor functioning of patients with PD.

\section{Material and methods}

\section{Study group}

We studied 20 (9 male, 11 female) consecutive patients who underwent bilateral stimulation of the subthalamic nucleus between May 2009 and April 2011. The selection criteria were (1) clinically diagnosed PD, (2) no surgical contraindications, (3) no dementia or major ongoing psychiatric illness and (4) no other neurological disorders. One patient was excluded from the study because of local infection. Nineteen subjects (age range: 37 to 72 years) were evaluated preoperatively and at the $5^{\text {th }}$ day and $6^{\text {th }}$ month after surgery. The stimulation was begun at the $2^{\text {nd }}$ day after surgery ( $5^{\text {th }}$ day) and we assessed all patients to show DBS's early effects. Additionally, we checked the long-term effects after surgery (6 $6^{\text {th }}$ month). The ethics committee of Pamukkale University in Turkey approved the study, and all the patients gave their written informed consent. The characteristics of the patients are summarized in Table I.

\section{Surgery procedure}

All STN DBS procedures were performed by one neurosurgeon in two stages: (1) insertion of bilateral electrodes under local anesthesia using microelectrode recording, and (2) connection of the electrodes to pulse generators under general anesthesia, performed approximately 1 day after lead placement. The operative technique was described in detail elsewhere [14]. The subthalamic nuclei were localized stereotactically by magnetic resonance imaging (MRI), and microelectrode recordings were performed to define the STN. Quadripolar electrodes (Medtronic 37601 Activa PC) were implanted bilaterally in all patients. Surgery was performed with local anesthesia and the clinical effect on rigidity and tremor was tested under stimulation using a macroelectrode. All patients underwent MRI postoperatively for the assessment of surgical complications. On the $2^{\text {nd }}$ day after implantation of the electrodes, a programmable pulse generator was implanted subcutaneously under general anesthesia. Stimulation settings and medication were progressively adjusted.

\section{Clinical assessment}

Patients were evaluated preoperatively and at the $5^{\text {th }}$ day and $6^{\text {th }}$ month after surgery Unblinded 
assessments were performed when patients had taken no medication for 8 to $12 \mathrm{~h}$ (off medication) in order to show the benefits of the STN DBS. Postoperatively, patients were assessed during on stimulation.

\section{Outcome measures}

An experienced PT assessed the patient with clinical performance tests, and the same PT assessed all patients in all test situations.

\section{Berg Balance Scale}

The Berg Balance Scale (BBS) was used to test balance performance and includes 14 items common in everyday life. All items are graded on a 5 -point ordinal scale from 0 to 4 . The maximum total score is 56 points, and a higher score reflects better performance. Scoring is based on the time a position can be maintained, the distance of forward reach, or the time to complete a task. The score per item is reduced as assistance increases, quality of performance decreases or if the time and distance requirements are not met [15].

\section{The timed up and go (TUG)}

The subject is sitting in an armchair (seat height of $46 \mathrm{~cm}$ ) with the back against the chair and arms resting on the chair's arms. The instruction ' $G o$ ' initiates the subject to stand up and walk at a comfortable pace to a line $3 \mathrm{~m}$ away, where both feet should pass the line before the subject turns around and walks back to sit down again. Timing commences when the subject's back leaves the back of the chair, and stops when the buttocks reach the seat of the chair. Average time required to complete the TUG test is reported [16].

\section{Chair-Stand Test (CST)}

The time required to stand up from a chair and to sit down consecutively as fast as possible is registered. The subject is sitting in an armchair (seat height of $46 \mathrm{~cm}$ ) with the back against the chair, and with arms folded across the chest. The subject's regular footwear is worn. The test begins with the command "Start now". Timing commences when the subject's back leaves the back of the chair, and stops when the subject's buttocks reach the chair at the $30^{\text {th }} \mathrm{s}$ and the number is recorded [17].

\section{$12 \mathrm{~m}$ Walking Test}

The subject is standing still and then walks at a comfortable (preferred) speed straight forward. The subject's regular footwear is used. Timing commences after the command 'Go' and stops when the subject passes the mark for $12 \mathrm{~m}$. One trial is performed. Average time required to complete the test is reported [13].

\section{Unified Parkinson's Disease Rating Scale (UPDRS)}

Patients were clinically assessed using the UPDRS. Different scores were extracted from this scale: the psychological status (items 1 and 4 of the UPDRS I), the activities of daily living (ADL) score (items 5 and 17 of the UPDRS II), the motor score (items 18-31 of the UPDRS III, including gait and postural stability parameters), and the dyskinesias score (items 32-35 of the UPDRS IV). The total UPDRS score was between 0 and 108; maximal worst value $=108$ [18].

\section{Hoehn and Yahr Scale (H\&Y)}

Hoehn and Yahr Scale is a commonly used system for describing how the symptoms of PD progress. The H\&Y original scale included stages 1 to 5. Stage 0: no signs of disease, stage 1: unilateral symptoms only, stage 2: bilateral symptoms and impairment of balance, stage 3: balance impairment, mild to moderate disease and physically independent, stage 4: severe disability, but still able to walk or stand unassisted, stage 5: needing a wheelchair or bedridden unless assisted [18].

All participants gave informed consent and the study was approved by the ethical board committee of Pamukkale University Medical Faculty (Ref. no. 67, date 03.04.2009). This study was supported by Pamukkale University Scientific Research Projects Foundation (Ref. no. 2009SBE003).

\section{Statistical analysis}

Statistical analysis were performed using the Statistical Package for the Social Sciences (SPSS version 13.0). The Kolmogorov-Smirnov test was used to test normality of distribution and all data were parametric. The repeated measures ANOVA test was applied to compare the mean scores of three assessments (preoperative, postoperative $5^{\text {th }}$ day and postoperative $6^{\text {th }}$ month). In addition, a paired $t$-test was also used to compare the results obtained during the preoperative stage, postoperative $5^{\text {th }}$ day and postoperative $6^{\text {th }}$ month. A level of $p<0.05$ was considered significant.

\section{Results}

The demographics and clinical characteristics of patients at baseline are shown in Table I. The BBS and TUG scores significantly improved at the postoperative $5^{\text {th }}$ day and postoperative $6^{\text {th }}$ month. At the same time, $12 \mathrm{~m}$ Walking Test score, UPDRS total and UPDRS part III scores significantly decreased (Table II). 
Table II. Mobility, balance and UPDRS assessment

\begin{tabular}{|lccccc|}
\hline Variables & Preop $(n=19)$ & Postop $5^{\text {th }}$ day $(n=19)$ & Postop 6 $^{\text {th }}$ month $(n=19)$ & $F$ & Value of $p^{*}$ \\
\hline Berg Balance Scale & $12.8 \pm 6.8 / 56$ & $26.2 \pm 5.7 / 56$ & $38.8 \pm 8.7 / 56$ & $200.63<0.001$ \\
\hline Timed Up\&Go Test [s] & $56.05 \pm 42.52$ & $41.05 \pm 33.66$ & $21.47 \pm 20.36$ & 12.65 & $<0.001$ \\
\hline Chair-Stand Test & $4.00 \pm 4.66$ & $7.31 \pm 3.87$ & $11.68 \pm 4.43$ & $24.21<0.001$ \\
\hline 12 m Walking Test [s] & $100.44 \pm 66.44$ & $57.10 \pm 39.69$ & $28.84 \pm 19.79$ & 27.56 & $<0.001$ \\
\hline H\&Y & $3.94 \pm 0.62$ & $2.63 \pm 0.59$ & $2.47 \pm 0.96$ & $49.08<<0.001$ \\
\hline UPDRS motor scores (Part III) & $29.15 \pm 13.70$ & $19.42 \pm 7.10$ & $10.05 \pm 6.67$ & $35.13<0.001$ \\
\hline Gait & $3.15 \pm 0.76$ & $2.21 \pm 0.63$ & $0.73 \pm 0.87$ & $72.17<0.001$ \\
\hline Postural stability & $2.80 \pm 0.82$ & $1.63 \pm 0.59$ & $0.78 \pm 0.63$ & $199.63<0.001$ \\
\hline UPDRS total & $98.26 \pm 37.69$ & $64.84 \pm 19.04$ & $39.36 \pm 18.85$ & $30.59<0.001$ \\
\hline
\end{tabular}

${ }^{*}$ Repeated measures ANOVA

Table III. Mobility, balance and UPDRS assessment

\begin{tabular}{|lcccccc|}
\hline Variables & \multicolumn{2}{c}{ Preop - postop } & Preop-postop $6^{\text {th }}$ month & Postop - Postop 6th month \\
\cline { 2 - 7 } & $t$ & $p^{*}$ & $t$ & $p^{*}$ & $t$ & $p^{*}$ \\
\hline Berg Balance Scale & 12.75 & $<0.001$ & -17.94 & $<0.001$ & -9.26 & $<0.001$ \\
\hline Timed Up\&Go Test [s] & 4.15 & 0.001 & 3.79 & 0.001 & 2.83 & 0.011 \\
\hline Chair-Stand Test & -6.93 & $<0.001$ & -5.58 & $<0.001$ & -3.50 & 0.003 \\
\hline 12 m Walking Test [s] & 4.57 & $<0.001$ & 5.74 & $<0.001$ & 4.59 & $<0.001$ \\
\hline H\&Y & 9.84 & $<0.001$ & 9.22 & $<0.001$ & 0.88 & 0.420 \\
\hline UPDRS motor scores (Part III) & -5.08 & $<0.001$ & 6.02 & $<0.001$ & 6.85 & $<0.001$ \\
\hline Gait & 5.85 & $<0.001$ & 9.85 & $<0.001$ & 7.63 & $<0.001$ \\
\hline Postural stability & 8.75 & $<0.001$ & 26.19 & $<0.001$ & 9.79 & $<0.001$ \\
\hline UPDRS total & 5.51 & $<0.001$ & 6.05 & $<0.001$ & 4.05 & 0.001 \\
\hline
\end{tabular}

*Paired t-test

Post hoc analysis showed that there were significant differences between preoperative, $5^{\text {th }}$ day, and $6^{\text {th }}$ month measurements $(p<0.05)$. At the $6^{\text {th }}$ month after surgery, the BBS score was increased from $12.84 \pm 6.89$ to $38.89 \pm 8.79$ ( $p<0.05)$. The TUG score and a $12 \mathrm{~m}$ Walking Test score significantly decreased after surgery $(p<0.05)$. Chair Stand Test score was greater after surgery $(p<0.05)$. The mobility and balance assessment scores at baseline, $5^{\text {th }}$ day and $6^{\text {th }}$ month after surgery are shown in Table III.

Compared to the preoperative baseline, the $5^{\text {th }}$ day and $6^{\text {th }}$ month UPDRS-III scores were significantly better $(p<0.05)$. All aspects of the motor symptoms (UPDRS-III) including gait and postural stability were significantly improved at the $6^{\text {th }}$ month after surgery $(p<0.05)$. The postural stability decreased from $2.80 \pm 0.82$ to $0.78 \pm 0.63$, showing a significant improvement at the $6^{\text {th }}$ month after surgery. Hoehn and Yahr Scale score was decreased from $3.94 \pm 0.62$ to $2.47 \pm 0.96$ at the $6^{\text {th }}$ month after surgery. Levodopa equivalents intake (LED) was reduced from a mean of $648.68 \pm 446.93 \mathrm{mg} /$ day to $209.21 \pm 191.8 \mathrm{mg} /$ day after 6 months. Compared to the preoperative value, $5^{\text {th }}$ day and $6^{\text {th }}$ month UPDRS total scores significantly improved $(p=0.000)$ (Table III).

\section{Discussion}

In this study the patients with advanced PD have been followed prospectively. After 6 months, STN DBS showed significant improvements in all Parkinsonian motor signs studied in this work. It has been observed that bilateral STN DBS improved the severe symptoms (i.e. balance and gait disturbances), which could not be managed with the most suitable drug therapy. For instance, bilateral STN stimulation significantly increased BBS score and gait velocity. At the same time, the participants performed the TUG and CST tests faster compared to before surgery. At the $6^{\text {th }}$ month after surgery, BBS increased by $216 \% .12 \mathrm{~m}$ Walking Test, and UPDRS motor and UPDRS-III gait scores improved by $257 \%, 65 \%$, and $76 \%$ respectively. Namely, bilateral STN DBS decreased all Parkinsonian symptoms, improving balance and walking ability of the patients. 
In Parkinson's disease, the basal ganglia (BG) input to the thalamus becomes pathological and relay of motor-related cortical inputs is compromised, thereby impairing movements. However, high frequency (HF) deep brain stimulation may be used to restore relay reliability, thereby restoring movements in PD patients. Although DBS is currently an effective therapy for $\mathrm{PD}$, the typical stimulation signal is a high-frequency train of pulses (> $100 \mathrm{~Hz}$ ) which consumes significant power [19]. In the present work, we used pulses of $90 \mu$ s duration and 2-4 $\mathrm{V}$ amplitude, delivered in the STN at $180-185 \mathrm{~Hz}$ frequency, which is the most important parameter for our patients. The DBS injects a current that modulates the neural activity of the diseased brain circuit, leading to a reversal of PD symptoms. When appropriately stimulated, patients can regain control of movement and reduce the use of medication [20].

Over the last decade high-frequency DBS has been the most preferred therapy for these patients. The most important advantage of DBS, in contrast to drug therapy, is that a constant level of stimulation can be maintained throughout the day. Moreover, there have been many studies showing that bilateral DBS of the STN improves the symptoms of PD including bradykinesia, tremor, rigidity, gait problem, balance disturbance and motor dysfunction $[9,21]$. Despite its benefits, surgical treatment should be combined with the pharmacological treatment. More importantly, physical therapy should be included in the treatment regime in order to reduce rigid postural symptoms and to improve gait velocity and balance ability.

Postural instability is one of the cardinal symptoms of PD, and persons with PD run an increased risk of falling. Most falls occur during functional activities, e.g. walking and turning [22]. According to Johnsena et al. [23] gait performance evaluated as velocity and step length improved significantly more with DBS dorsal stimulation compared with ventral stimulation. Balance was improved, as time spent in the double support phase decreased from 21.40 to 15.36 . Also, measures of gait hypokinesia in hip, knee and ankle-joint range of motion were improved significantly. A recent study showed that 12 months after stimulation it resulted in improved scores for akinesia, rigidity, tremor, impairment of arising from a chair, gait and postural instability, when patients were evaluated off medication and on medication [24].

Kelly investigated the effects of unilateral and bilateral subthalamic nucleus stimulation on gait and mobility in PD. They found that bilateral and unilateral STN DBS are effective for mobility and gait function [25]. Nilsson et al. demonstrated that 63\% of patients increased their total score of the BBS and the postural stability item of the UPDRS-III with
STN stimulation alone 3 years after surgery. Thus, STN stimulation alone has a long-term, positive effect on functional balance performance [3]. Another study also showed that UPDRS-III scores improved with either unilateral dorsal or ventral DBS, compared with the DBS off-on period [26]. Hamani et al. [27] reported an improvement of $64 \%$ for gait and $69 \%$ for postural stability 1 year after surgery. Bejjani et al. [28] also concluded that, 6 months after surgery, axial parkinsonian symptoms, including freezing of gait, can be improved by STN stimulation.

According to our results, all the patients' mobility and balance ability (Timed Up and Go Test, $12 \mathrm{~m}$ Walking Test, Chair Stand Test and BBS) improved at the $6^{\text {th }}$ month after surgery significantly $(p<0.05)$. UPDRS-III total score, gait and postural stability scores improved 6 months after surgery significantly $(p<0.05)$. Our results are similar to those reported in the literature.

Rodriguez-Oroz et al. found that with STN stimulation the daily dosage of levodopa was significantly reduced $(p<0.001)$ [29]. In our results, LED was reduced from a mean of $648.6 \pm 446.9 \mathrm{mg} /$ day to $209.21 \pm 191.8 \mathrm{mg} /$ day after 6 months. This result was also approved by the neurologist. The DBS (STN-S) is an effective treatment for the functional capacity in PD. In a recent study, compared with baseline, the patients' scores at five years for motor function while off medication improved by $54 \%$ $(p<0.001)$ [30]. Tir et al. reported a decrease by $43 \%$ in UPDRS-III scores 12 months after surgery [31]. Our results are in line with the literature. UPDRS-III scores had significantly decreased 6 months after surgery. Gait and postural stability were significantly improved after surgery $(p<0.05)$. At 6 months after surgery, the H\&Y score was decreased from 3.94 \pm 0.62 to $2.47 \pm 0.96(p<0.05)$.

Major results emerged from this study: surgery has significant positive effects on gait ability and balance performance in patients with PD. A weakness of this study is that we did not follow longterm outcomes of mobility and balance performance and we do not have a control group. Long-term follow-up might possibly contribute to detection of greater changes in mobility and balance assessment.

A weakness of this study is that we did not follow longterm outcomes of mobility and balance performance and we gaved a preliminary results in this study and we do not have a control group. Long term follow-up might possibly contribute to detection of greater changes in mobility and balance.

\section{References}

1. Pincus JH. Management of persons with Parkinson's disease: In: Management of Parkinson's with Chronic Neurologic Illness. Ozer MN (ed.). Boston 2000; 213-2. 
2. Chapuis S, Ouchchans L, Metz O, Gerbaud L, Durif F. Impact of the motor complications of Parkinson's disease on the quality of life. Mov Disord 2005; 20: 224-30.

3. Nilsson $\mathrm{MH}$, Tornqvist AL, Rehncrona S. Deep-brain stimulation in the subthalamic nuclei improves balance performance in patients with Parkinson's disease, when tested without anti-parkinsonian medication. Acta Neurol Scand 2005; 111: 301-8.

4. Bloem BR, Hausdorff JM, Visser JE, Giladi N. Falls and freezing in Parkinson's disease: a review of two interconnected, episodic phenomena. Mov Disord 2004; 19 : 871-84.

5. Bronstein AM, Brandt T, Nutt JG, Woollacott MH. Clinical disorders of balance, posture and gait. In: Gait and balance in basal ganglia disorders. Bloem BR, Bhatia KP (eds.). Arnold, London 2004; pp. 173-206.

6. Nelson ME, Rejeski WJ, Blair SN, et al. Physical activity and public health in older adults: recommendation from the American College of Sports Medicine and the American Heart Association. Med Sci Sports Exerc 2007; 39: 1435-45.

7. Dalgas U, Stenager E, Jakobsen J, et al. Resistance training improves muscle strength and functional capacity in multiple sclerosis. Neurology 2009; 73: 1478-84.

8. Tillerson JL, Claudle WM, Reveron ME, Miller GW. Forced nonuse in unilateral parkinsonian rats exacerbates injury. J Neurosci 2002; 22: 6790-9.

9. Vrancken AM, Allum JH, Peller M, et al. Effect of bilateral subthalamic nucleus stimulation on balance and finger control in Parkinson's disease. J Neurol 2005; 252: 1487-94.

10. Sofuwa O, Nieuwboer A, Desloovere K, Willems AM, Chavret F, Jonkers I. Quantitative gait analysis in Parkinson's disease: comparison with a healthy control group. Arch Phys Med Rehabil 2005; 86: 1007-13.

11. Bakker M, Esselink RA, Munneke M, Limousin-Dowsey P, Speelman HD, Bloem BR. Effects of stereotactic neurosurgery on postural instability and gait in Parkinson's disease. Mov Disord 2004; 19: 1092-9.

12. Johnsen EL, Mogensen PH, Sunde NA, Østergaard K. Improved asymmetry of gait in Parkinson's disease with DBS: gait and postural instability in Parkinson's disease treated with bilateral deep brain stimulation in the subthalamic nucleus. Mov Disord 2009; 24: 590-7.

13. Altuğ F, Acar F, Acar G, Cavlak U. The influence of subthalamic nucleus deep brain stimulation on physical, emotional, cognitive functions and daily living activities in patients with Parkinson's disease. Turk Neurosurg 2011; 21: 140-6.

14. Goetz CG, Koller WC, Poewe W, Rascol O, Sampaio C. Management of Parkinson's disease: an evidence-based review. Mov Disord 2002; 17 Suppl 4: S1-166.

15. Qutubuddin AA, Pegg PO, Cifu DX, Brown R, McNamee S, Carne W. Validating the Berg Balance Scale for patients with Parkinson's disease: a key to rehabilitation evaluation. Arch Phys Med Rehabil 2005; 86: 789-92.

16. Shumway-Cook A, Brauer S, Woollacott M. Predicting the probability for falls in community-dwelling older adults using the Timed Up \& Go Test. Phys Ther 2000; 80: 896-903.

17. Jones CJ, Rikli RE, Beam WC. A 30-s chair-stand test as a measure of lower body strength in community-residing older adults. Res Q Exerc Sport 1999; 70: 113-9.

18. Moro E, Hamani C, Poon YY, Al-Khairallah T, Dostrovsky JO, Hutchison WD, Lozano AM. Unilateral pedunculopontine stimulation improves falls in Parkinson's disease. Brain 2010; 133: 215-24.
19. Agarwal R, Sarma SV. The effects of DBS patterns on basal ganglia activity and thalamic relay: a computational study. J Comput Neurosci 2012; 33: 151-67.

20. Kleiner-Fisman G, Herzog J, Fisman DN et al. Subthalamic nucleus deep brain stimulation: summary and metaanalysis of outcomes. Mov Disord 2006; 14: S290-304.

21. Tykocki T, Mandat T, Nauman P. Pedunculopontine nucleus deep brain stimulation in Parkinson's disease. Arch Med Sci 2011; 7: 555-64.

22. Nilsson MH, Fransson PA, Jarnlo GB, Magnusson M Rehncrona S. The effects of high frequency Subthalamic stimulation on balance performance and fear of falling in patients with Parkinson's disease. J Neuroeng Rehabil 2009; 6: 13.

23. Johnsena EL, Sundeb N, Mogensenc PH, Østergaarda K. $M R I$ verified STN stimulation site - gait improvement and clinical outcome. Eur J Neurol 2010; 17: 746-53.

24. Patel NK, Plaha P, Sullivan K, McCarter R, Heywood P, Gill SS. MRI directed bilateral stimulation of the Subthalamic Nucleus in patients with Parkinson's disease. J Neurol Neurosurg Psychiatry 2003; 74: 1631-7.

25. Kelly VE, Israel SM, Samii A, Slimp JC, Goodkin R, Shumway CA. Assessing the effects of Subthalamic Nucleus Stimulation on gait and mobility in people with Parkinson disease. Dis Rehabil 2010; 32: 929-36.

26. McNeely ME, Hershey T, Campbell MC et al. Effects of deep brain stimulation of dorsal versus ventral subthalamic nucleus regions on gait and balance in Parkinson's disease. J Neurol Neurosurg Psychiatry 2011; 82: 1250-5.

27. Hamani C, Richter E, Schwalb JM, Lozano AM. Bilateral subthalamic nucleus stimulation for Parkinson's disease: a systematic review of the clinical literature. Neurosurgery 2005; 56: 1313-21.

28. Bejjani BP, Gervais D, Arnulf I, et al. Axial parkinsonian symptoms can be improved: the role of levodopa and bilateral subthalamic stimulation. J Neurol Neurosurg Psychiatry 2000; 68: 595-600.

29. Rodriguez-Oroz MC, Zamarbide I, Guridi J, Palmero MR, Obeso JA. Efficacy of deep brain stimulation of the Subthalamic Nucleus in Parkinson's disease 4 years after surgery: double blind and open label evaluation. J Neurol Neurosurg Psychiatry 2004; 75: 1382-5.

30. Krack P, Batir A, Van Blercom N, et al. Five-year follow-up of bilateral stimulation of the subthalamic nucleus in advanced Parkinson's disease. N Engl J Med 2003; 349: 925-34.

31. Tir M, Devos D, Blond S, Touzet, G, Reyns, N, Duham EL. One-year follow-up of subthalamic nucleus deep brain stimulation in a large, single-center cohort of Parkinsonian patients. Neurosurgery 2007; 61: 297-304. 